www.jmscr.igmpublication.org

Impact Factor 5.84

Index Copernicus Value: 71.58

ISSN (e)-2347-176x ISSN (p) 2455-0450

crossref DOI: https://dx.doi.org/10.18535/jmscr/v5i11.204

Journal Of Medical Science And Clinical Research

\title{
Morphological Assessment of Maxillary Sinus Volume in Gender Differentiation
}

\author{
Authors \\ Hassan Mohammad, Anand A.M, Dr N. Kulasekaran \\ SMVMCH
}

\begin{abstract}
Background: The maxillary sinuses are the largest of the facial cavities. Depending on the individual's age, its volume varies. between small, average or large sinuses. Communication of this sinus with the nasal fossa is through a canal called the ostium which has its opening at the nasofrontalis duct. The high placement of this canal favors the origin of several sinus pathologies. The aim of this study is to calculate the maxillary sinus volume by measuring the Antero-posterior, Medio-lateral and Cranio-caudal distances of the maxillary sinus andto compare the morphology of maxillary sinus between the right and the left sides in males and females. Additionally the location of maxillary ostium was also assessed.

Materials and Methods: Our study involved 80 adults who were referred to the department of radiodiagnosis for complaints related to paranasal sinuses. Computed tomography (CT) images of paranasal sinus anatomy was obtained in coronal and sagittal planes. Measurements of the maximum cranio-caudal, transverse and anteroposterior diameters were measured. The opening of the sinus ostium (upper, middle, or lower third) was obtained.

Results: In our study, the average maxillary sinus volume on the right side was found to be $40.7 \%$ more in the male population as compared to the females whereas on the left side, it was found to be 50.3\%. This suggests that the maxillary volume can be used as a relatively accurate method to determine the gender. Of the 100 adults, maxillary ostium was located in the upper 1/3rd in 84, and in the middle 1/3rd in 16. None of the adults had a lower 1/3rd opening of the maxillary ostium.

Conclusion: Significant difference exist in the maxillary volume between males and females, with the left maxillary sinus showing a more greater difference. The maxillary ostium is situated in the upper 1/3rd majority of patients. CT of paranasal sinuses is a useful in assessing these observations.
\end{abstract}

\section{Introduction}

Development of the maxillary sinus occurs symmetrically. The ostium of the maxillary sinus initially opens into the infundibulum. The infundibulum then joins the hiatus semilunaris followed by which they collectively drain into the middle meatus. The frontal sinus ostium, frontal sinus drainage pathway (FSDP), maxillary sinus ostium, infundibulum, and middle meatus together constitute the complex anterior osteomeatal unit. A common connection between the frontal, 
anterior ethmoid and maxillary sinuses is established through these structures.

Different variations of the maxillary sinuses with regards to the size, shape, and position are seen in different individuals and also in different sides of the same individual ${ }^{[1]}$. The measurements and volume of the maxillary sinus vary considerably in ethnic groups ${ }^{[2]}$. Due to the anatomical variability of the maxillary sinus and its close relation to the maxillary posterior teeth, assessment of the dimensions of the maxillary sinus is of utmost usefulness ${ }^{[3]}$. The maxillary sinus ostium is on the situated in the superior most part of the medial wall of the sinus and, is therefore, poorly situated from the point of view of free drainage. Inflammation of the ostium can further interfere with drainage as it opens into the narrow infundiubulum and not directly into the nasal fossa. ${ }^{[4][5]}$.

\section{Material and Methods}

This retrospective study was carried out in Sri Manakula Vinayagar Medical College and Hospital for a period of 6 months between June to November 2016 who were referred to Department of Radiodiagnosis for symptoms related to sinonasal disease but without evidence of pathology in maxillary sinuses. Pilot study was conducted to ascertain the sample size, after which the sample size was set at 80. Ethical clearance was obtained from the Research and Ethics Committee prior to commence of the study. Adults with history of head trauma, previous surgeries and children ( $<12$ years) were excluded from the study.

The study was done using Philips MX16 CT of 80 adults. Axial scans were taken in $1 \mathrm{~mm}$ thin section collimation with sagittal and coronal reconstruction to $5 \mathrm{~mm}$ thickness. From the axial images, the maximum distance from anterior wall to posterolateral wall were used to calculate the Anteroposterior distance, whereas the maximum distance from the medial wall to the lateral wall of the maxuillary sinus was used to measure the transverse distance. From the coronal reformatted images, maximum distance from the maxillary roof to the maxillary floor was used to measure the Craniocaudal distance (Image 1). Formula used was Anteroposterior (AP) X Mediolateral (ML) x Craniocaudal (CC) / 2.

The maxillary ostium was assessed in the coronal reformatted images and after dividing the sinus into equivalent parts were further classified into as originating in the upper $1 / 3 \mathrm{rd}$, middle $1 / 3 \mathrm{rd}$ or lower $1 / 3$ rd of the maxillary sinus.

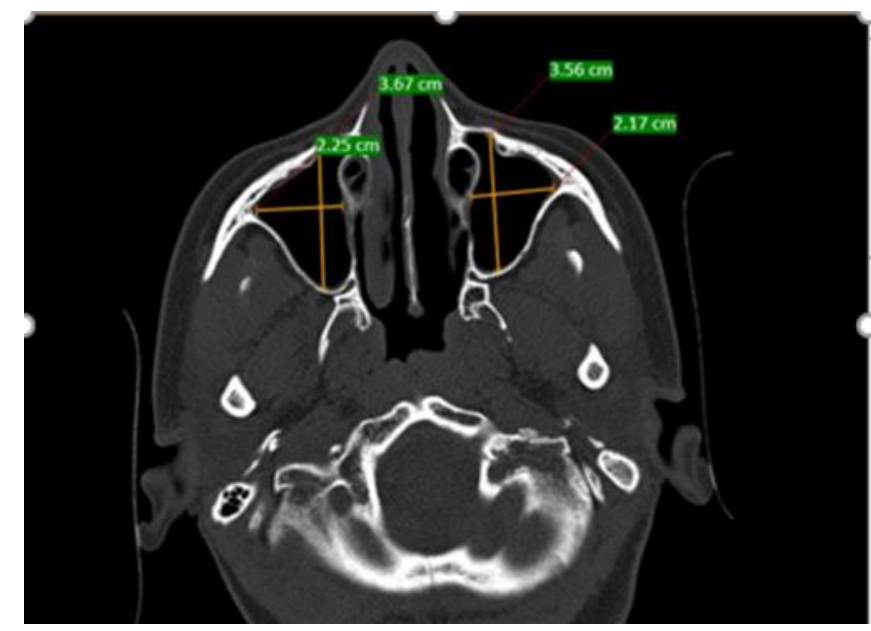

A.

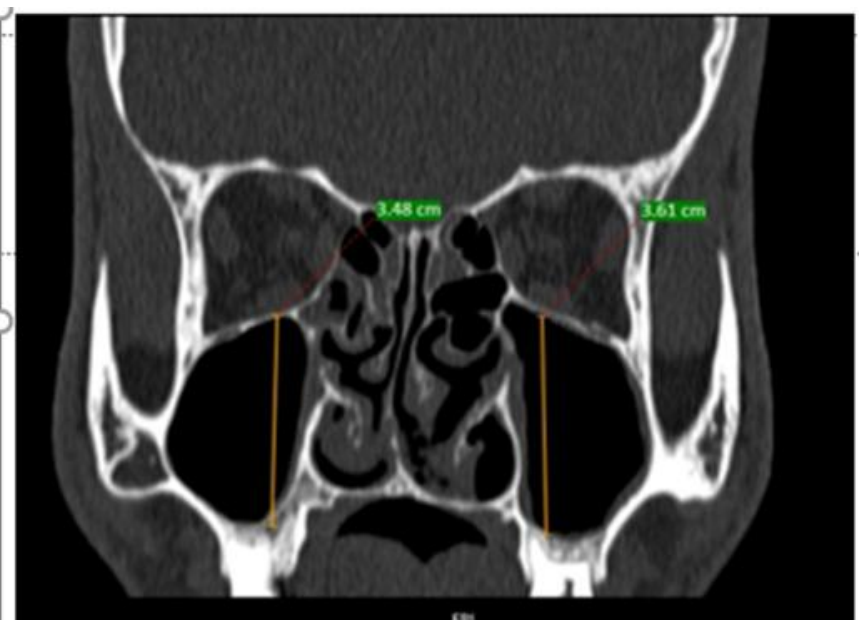

B.

Image 1. A. Axial CT at the level of maxillary sinus showing the maximum Antero-posterior and transverse distance. B. Coronal reformatted image showing the maximum craniocaudal distance. 


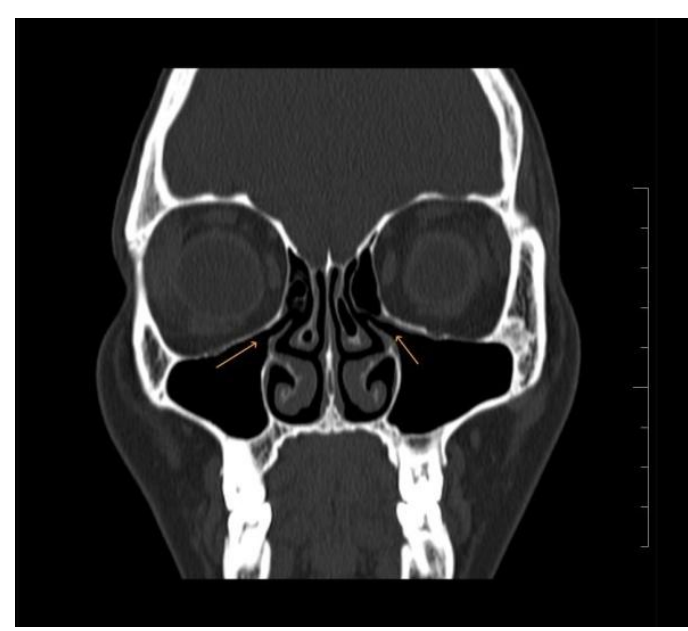

A.

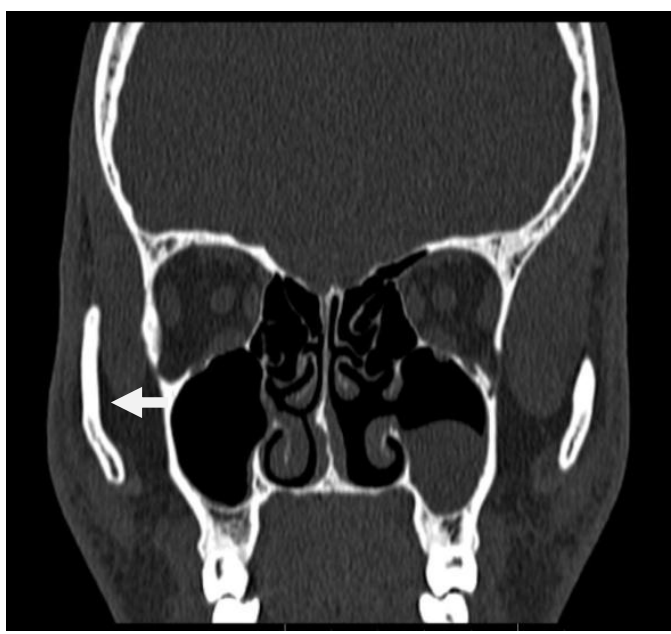

B.

Image 2. A. Axial CT at the level of maxillary sinus showing the bilateral maxillary ostium at the superior 1/3rd. B. Left maxillary ostium opening at middle 1/3rd.

\section{Results}

CT images of 100 patients were included in the study, of which 45 were males and 55 females. Their age group ranged from 14 to 77 years.

\begin{tabular}{|l|c|c|c|c|}
\hline Measurements & \multicolumn{2}{|c|}{ Males (n=35) } & \multicolumn{2}{c|}{ Females (n=45) } \\
\hline & $\begin{array}{c}\text { Right } \\
\text { (Mean) }\end{array}$ & $\begin{array}{c}\text { Left } \\
(\text { Mean })\end{array}$ & $\begin{array}{c}\text { Right } \\
(\text { Mean })\end{array}$ & $\begin{array}{c}\text { Left } \\
(\text { Mean })\end{array}$ \\
\hline Anteroposterior & 3.98 & 3.74 & 3.44 & 3.64 \\
\hline Mediolateral & 2.66 & 2.78 & 2.4 & 2.12 \\
\hline CC & 3.7 & 3.6 & 2.78 & 10.4 \\
\hline
\end{tabular}

\begin{tabular}{|l|l|l|l|l|}
\hline & \multicolumn{2}{|c|}{ Males (n=35) } & \multicolumn{2}{c|}{ Females (n=45) } \\
\hline & Right & Left & Right & Left \\
\hline Maxillary sinus volume & 23.76 & 18.9 & 14.48 & 9.62 \\
\hline
\end{tabular}

The maxillary sinus volumes were measured in 35 cc in females. Left side maxillary sinuses had an females and 45 females.

Right sided maxillary sinuses of males had an average volume of $18.9 \mathrm{cc}$ compared $9.62 \mathrm{cc}$ in females.

average volume of $23.7 \mathrm{cc}$ as compared to 14.48

\begin{tabular}{|l|c|c|c|}
\hline & Upper 1/3rd & Middle 1/3rd & Lower 1/3rd \\
\hline Location of Maxillary Ostium & 68 & 12 & 0 \\
\hline
\end{tabular}

Of the 80 cases, maxillary ostium was located in the upper $1 / 3^{\text {rd }}$ in 68 , in middle $1 / 3^{\text {rd }}$ in 12 . None of the cases had a lower $1 / 3^{\text {rd }}$ opening of the maxillary ostium.

\section{Discussion}

This study was done to assess the maxillary sinus volume in males and females. Significant difference in the size of the volumes were identified in both genders, with the left maxillary sinus volume being consistently greater the right. The maxillary sinuses are present at birth and at

infancy, their longer measurements are directed anteriorly and posteriorly and measure about 8 $\mathrm{mm} \times 4 \mathrm{~mm}$. On an average, the measurements of the adult sinus range from 2.5 to $3.5 \mathrm{~cm}$ wide, 3.6 to $4.5 \mathrm{~cm}$ height, and $3.8-4.5 \mathrm{~cm}$ depth ${ }^{[6]}$. Also, the usual volume is approximately 12 to $15 \mathrm{~cm}$ ${ }^{[2,14]}$. At adult stage, their shapes and sizes vary considerably, especially due to loss of teeth. It has been described that genetic diseases, infections and environmental factors have an effect on the size of the maxillary sinuses ${ }^{[7,8]}$. 
Maxillary sinus anatomy is complex and has significant variation from one person to another ${ }^{[9,10]}$. In our present study, there is a considerable difference between the two sides as well as between genders. This suggests that the maxillary sinus dimensions could be a reliable source for determination of gender ${ }^{[11]}$. In this regard, CT calculations of maxillary sinuses, that is, the anteroposterior, the transverse, and the craniocaudal dimensions can be useful tool gender determination in forensic medicine.

In a study done by Reham et al, it was found that the largest average craniocaudal, mediolateral, and anteroposterior extensions of the maxillary sinus were $3.55,2.04$, and 3.15 respectively ${ }^{[12]}$. Another study which had similar average dimension of the maxillary sinuses was that of Tiwana et al ${ }^{[13]}$. It stated that $33 \mathrm{~mm}$ (Craniocaudal), $23 \mathrm{~mm}$ (Mediolateral), and $34 \mathrm{~mm}$ (Anteroposterior) were the average measurements of the maxillary sinus. Moreover, the study of maxillary sinus using high resolution CT by Shahbazian et al ${ }^{[14]}$ revealed that the anteroposterior and mediolateral measurements of the maxillary sinuses were in the range of $38 \mathrm{~mm}$ and $23.5 \mathrm{~mm}$, respectively. However, their study did not mention information about the craniocaudal extension of the sinus

In our study, the average maxillary sinus volume on the right side was found to be $40.7 \%$ more in the male population as compared to the females whereas on the left side, it was found to be $50.3 \%$. This suggests that the maxillary volume can be used as a relatively accurate method to determine the gender.

\section{Conclusion}

The location of Maxillary sinus ostium was identified, dimensions of maxillary sinus were noted and the distances were measured. The most common location of the ostium was in the upper third. The dimensions of the maxillary sinus indicated bilateral asymmetry and there were significant gender differences in our study. Variability in the morphology of the maxillary sinus has detrimental significance during surgical procedures and to reduce the risk of post-operative complications.

\section{References}

1. Standring S, Borley NR, Collins P, Crossman AR, Gatzoulis MA, Healy JC, et al. Gray's Anatomy: The Anatomical Basis of Clinical Practice. 40th ed. New York, NY: Churchill Livingstone; 2008. p. 547-60.

2. Chanavaz M. Maxillary sinus: Anatomy, physiology, surgery, and bone grafting related to implantology - Eleven years of surgical experience (1979-1990). J Oral Implantol1990;16:199-209.

3. Hamdy RM, Abdel-Wahed N. Three dimensional linear and volumetric analysis of maxillary sinus pneumatization. $\mathrm{J} \mathrm{Adv}$ Res 2014;5:387-95.

4. Kumar H, Choudhry R, Kakar S. Accessory maxillary Ostia: Topography and clinical application. $\mathbf{J}$ AnatSoc India 2001;50:3-5.

5. Hollinshed WH, Rosse C. Text Book of Anatomy. 4th ed. Philadelphia: Herper and Row; 1985. p. 976-85.

6. van den Bergh JP, ten Bruggenkate CM, Disch FJ, Tuinzing DB. Anatomical aspects of sinus floor elevations. Clin Oral Implants Res 2000;11:256-65.

7. Cordioli G, Mazzocco C, Schepers E, Brugnolo E, Majzoub Z. Maxillary sinus floor augmentation using bioactive glass granules and autogenous bone with simultaneous implant placement. Clinical and histological findings. Clin Oral Implants Res 2001;12:270-8.

8. Karakas S, Kavakli A. Morphometric examination of the paranasal sinuses and mastoid air cells using computed tomography. Ann Saudi Med 2005;25:41-5.

9. Miller AJ, Amedee RG. Functional anatomy of the paranasal sinuses. J La State Med Soc1997;149:85-90. 
10. Amedee R. Sinus anatomy and function. In: Bailey BJ, editor. Head and Neck Surgery Otolaryngology. Vol. 1. Philadelphia: J.B. Lippincott Company; 1993. p. 342-9.

11. Uthman AT, Al-Rawi NH, Al-Naaimi AS, Al-Timimi JF. Evaluation of maxillary sinus dimensions in gender determination using helical CT scanning. J Forensic Sci 2011;56:403-8.

12. Hamdy, R. and Abdel-Wahed, N. (2014). Three-dimensional linear and volumetric analysis of maxillary sinus pneumatization. Journal of Advanced Research, 5(3), pp.387-395

13. P.S. Tiwana, G.M. Kushner, R.H. Haug, Maxillary sinus augmentation, Dent Clin North Am, 50 (2006), pp. 409-424

14. M. Shahbazian, D. Xue, Y. Hu, J. Cleynen breuge, R. Jacobs Spiral computed tomography based maxillary sinus imaging in relation to tooth loss, implant placement and potential grafting procedure, $\mathrm{J}$ Oral Maxillofac Res, 1 (1) (2010), p. e7, 10.5037/jomr.2010.1107. 